\title{
Pinch, Burn, Cut Parathyroid-sparing Thyroidectomy Saves Recurrent and Superior Laryngeal Nerves (Conventional, PBC and Harmonic Scalpel Techniques Compared)
}

\author{
${ }^{1}$ Raghavendra G Prasad, ${ }^{2}$ JV Subba Rao, ${ }^{3}$ Mohammed Abdul Rahman Hameed
}

\begin{abstract}
Introduction: Recurrent laryngeal nerve (RLN) and superior laryngeal nerve (SLN) have been and continue to be the Achilles tendon of thyroidectomy. Many anatomical landmarks described and taught.
\end{abstract}

Keywords: Burn, Conventional thyroidectomy, Cut parathyroidsparing thyroidectomy, Goiter, Pinch.

How to cite this article: Prasad RG, Rao JVS, Hameed MAR. Pinch, Burn, Cut Parathyroid-sparing Thyroidectomy Saves Recurrent and Superior Laryngeal Nerves (Conventional, PBC and Harmonic Scalpel Techniques Compared). Int J Phonosurg Laryngol 2015;5(2):48-52.

Source of support: Nil

Conflict of interest: None

\section{INTRODUCTION}

Recurrent laryngeal nerve (RLN) has been Achilles tendon in the surgery of thyroid. Attempts to increase safety of RLN are being made, constantly over years by anatomical studies, relating and localizing RLN to tubercle of Zuckerkandl, relation to inferior thyroid artery, searching in RLN triangle and so on.

Surgical principles like 'on the pole-superior pedicle' and 'away from the pole-inferior pedicle' of thyroid as anatomical standard steps of conventional thyroidectomy to prevent injury to RLN and superior laryngeal nerve (SLN).

Superior laryngeal nerve was advocated and taught. Despite strict adherence to these principles, RLN continues

${ }^{1}$ Professor, ${ }^{2}$ Anesthesiologist, ${ }^{3}$ Junior Resident

${ }^{1}$ Department of Pediatric Surgery, Princess Esra Hospital, Deccan College of Medical Sciences, Hyderabad, Telangana, India

${ }^{2}$ Department of Anesthesia, Princess Esra Hospital, Deccan College of Medical Sciences, Hyderabad, Telangana, India

${ }^{3}$ Department of Pediatric Surgery, Deccan College of Medical Sciences, Hyderabad, Telangana, India

Corresponding Author: Raghavendra G Prasad, Professor Department of Pediatric Surgery, 3-9-14 Sharada Nagar Ramanthapur, Hyderabad-500013, Telangana, India, Phone: 09849096145, e-mail: grprasad22@gmail.com to be at significant risk with conventional thyroidectomy. Intraoperative nerve stimulation (IONS) was yet another recent technical advance to reduce RLN injury. Use of harmonic scalpel and IONS has been tried but not costeffective and unavailable at all places. Author adopted pinch, burn, cut (PBC) on surface of thyroid as tool to avoid RLN and SLN injury. The technique confines to surgical plane just on surface of thyroid where the smaller arterioles enter parenchyma. This plane also is distal to parathyroids and these glands were never exposed to ischemic injury.

\section{AIMS AND OBJECTIVES}

To describe authors PBC technique in detail and to compare RLN and SLN safety with the three procedures adopted, namely conventional thyroidectomy, parathyroid sparing surface thyroidectomy and thyroidectomy using harmonic scalpel.

\section{MATERIALS AND METHODS}

This is a prospective operative 'procedure controlled' cohort of 192 thyroidectomies performed over 30 years. Redo thyroidectomies after hemithyroidectomy were also included.

\section{Exclusion Criteria}

All patients referred after thyroidectomy for recurrence or complications.

All patients having preoperative vocal cord palsy on direct laryngoscopy.

All patients had thyroid function tests, preoperative direct laryngoscopy, ultrasound of neck. Fine-needle aspiration cytology was done when indicated. Thyroid stimulating hormone was brought to normal in cases of toxic goiter or nodule.

\section{Technique of PBC}

The entire dissection of thyroid is on its surface beyond the main division of superior and inferior thyroid arteries into anterior and posterior and inferior and superior branches respectively. The vessels are coagulated just before they enter the parenchyma, meaning as small 
vessels that can be taken care of by diathermy. The RLNs and SLNs are, therefore, away and unlikely to be injured even by diathermy heat. Dissection is also distal to parathyroids and avoid ischemic injury to parathyroids and postoperative hypoparathyroidism. The author refers to this (PBC) as parathyroid sparing thyroidectomy.

The patients were divided into three groups:

Group A ( $n=94)$ : Open conventional thyroidectomies

Group $B(n=87)$ : Pinch, burn, cut parathyroid sparing surface thyroidectomies

Group C $(n=11)$ : Thyroidectomies using hand-held harmonic scalpel for dissection.

All the thyroidectomies were performed by the senior author in the team. Table 1 shows the patient groups. Table 2 shows the indications of thyroidectomy.

The records of those thyroidectomies were analyzed with the following parameters:

- Blood loss

- Duration of surgery

- Need of drain

- Recurrent laryngeal nerve injury

- Postoperative hypoparathyroidism

- Secondary hemorrhage

- Superior laryngeal nerve palsy.

Table 3 shows the results of these parameters studied.

Commonest indication was multinodular goiter followed by papillary carcinoma thyroid and follicular neoplasm. In the first few years, conventional thyroi-

Table 1: Sex and number of patients

\begin{tabular}{lllll}
\hline Sex & $\begin{array}{l}\text { Group } A \\
(n=94)\end{array}$ & $\begin{array}{l}\text { Group B } \\
(n=87)\end{array}$ & $\begin{array}{l}\text { Group C } \\
(n=11)\end{array}$ & Total \\
\hline Male & 44 & 40 & 2 & 86 \\
Female & 50 & 47 & 9 & 106 \\
\hline Total & 94 & 87 & 11 & 192 \\
\hline
\end{tabular}

Table 2: Indications of thyroidectomy

\begin{tabular}{lllll}
\hline Groups & $\begin{array}{l}\text { Multinodular } \\
\text { goiter }\end{array}$ & $\begin{array}{l}\text { Solitary } \\
\text { nodule }\end{array}$ & $\begin{array}{l}\text { Carcinoma } \\
\text { thyroid }\end{array}$ & $\begin{array}{l}\text { Follicular } \\
\text { neoplasm }\end{array}$ \\
\hline Group A $(\mathrm{n}=94)$ & 60 & 22 & 10 & 2 \\
Group B $(\mathrm{n}=87)$ & 40 & 30 & 10 & 7 \\
Group C $(\mathrm{n}=11)$ & 9 & 2 & 0 & 0 \\
\hline Total & 109 & 54 & 20 & 9 \\
\hline
\end{tabular}

dectomy was the preferred procedure. The stress was laid upon ligating the superior pedicle almost on the gland and inferior pedicle slightly away from the gland. A routine attempt was made to localize RLN using anatomical pointer's like tubercle of Zukerkandl, inferior thyroid arteries and searching in trachea esophageal groove. Later, the senior author shifted to pinch, burn cauterize technique of all the vessels on the surface of thyroid before they enter the gland tissue. Pedicles were not ligated. Hemostasis was achieved by use of low values on electrocautery. The plane of dissection is shown in Figures 1A to I shows the operative dissection. Videos 1 and 2 show actual PBC parathyroid sparing thyroidectomy. Hand-held harmonic scalpel was used for dissection in 11 patients. The pedicles were dissected and divided by harmonic scalpel as in conventional thyroidectomy. A routine suction drain was kept in all the open cases and in some cases of PBC parathyroid sparing surface thyroidectomy. Parathyroid was always spared with surface thyroidectomy technique.

\section{RESULTS}

Groups A, B and C had 94, 87 and 11 patients respectively. Most common indication for thyroidectomy was multinodular goiter in all the groups.

Recurrent laryngeal nerve was injured at the end of surgery temporarily in five and permanently in four in group A.

One suspected temporary palsy and no permanent injury in group B.

Temporary RLN palsy in and one permanent palsy in group C.

Blood loss was 100 to $500 \mathrm{ml}$ in group A, $10 \mathrm{ml}$ in group B and $25 \mathrm{ml}$ in group C.

The time taken for surgery was at an average 130, 90 and 120 minutes in groups $\mathrm{A}, \mathrm{B}$ and $\mathrm{C}$ respectively.

All cases of conventional thyroidectomy had a suction drain kept in situ, while PBC parathyroid sparing surface thyroidectomy did not need a drain in most cases and the drain was used only in four cases in group B and only one case in group $\mathrm{C}$.

Table 3: Recurrent laryngeal nerve and superior laryngeal nerve injuries with paired t-test results

\begin{tabular}{lllll}
\hline Parameters & Group $A(n=94)$ & Group B $(n=87)$ & Group C $(n=11)$ & Paired $t$-test \\
\hline Blood loss average & $100-500 \mathrm{ml}$ & $5-10 \mathrm{ml}$ & $10-25 \mathrm{ml}$ & $<0.05$ \\
Duration & $120-130 \mathrm{minutes}$ & 90 minutes & $100-120$ minutes & $<0.05$ \\
Need drain & Yes all $94=100 \%$ & $4 / 87=4.59 \%$ & $1 / 11=9.09 \%$ & $<0.05$ \\
RLN injury & $4 / 94=4.25 \%$ & $0 / 87=0 \%$ & $1 / 11=9.09 \%$ & $<0.05$ \\
Postoperative & $34 / 94=3.61 \%$ & $1 / 87=1.14 \%$ & $6 / 11=54.54 \%$ & $<0.05$ \\
hypoparathyroidism & & & & \\
Secondary hemorrhage & $2 / 94=2.12 \%$ & $0 / 87=0 \%$ & $1 / 11=9.09 \%$ & $<0.05$ \\
SLN palsy & $6 / 94=6.38 \%$ & $0 / 87=0 \%$ & $3 / 11=27.27 \%$ & $<0.05$ \\
\hline
\end{tabular}

RLN: Recurrent laryngeal nerve; SLN: Superior laryngeal nerve 


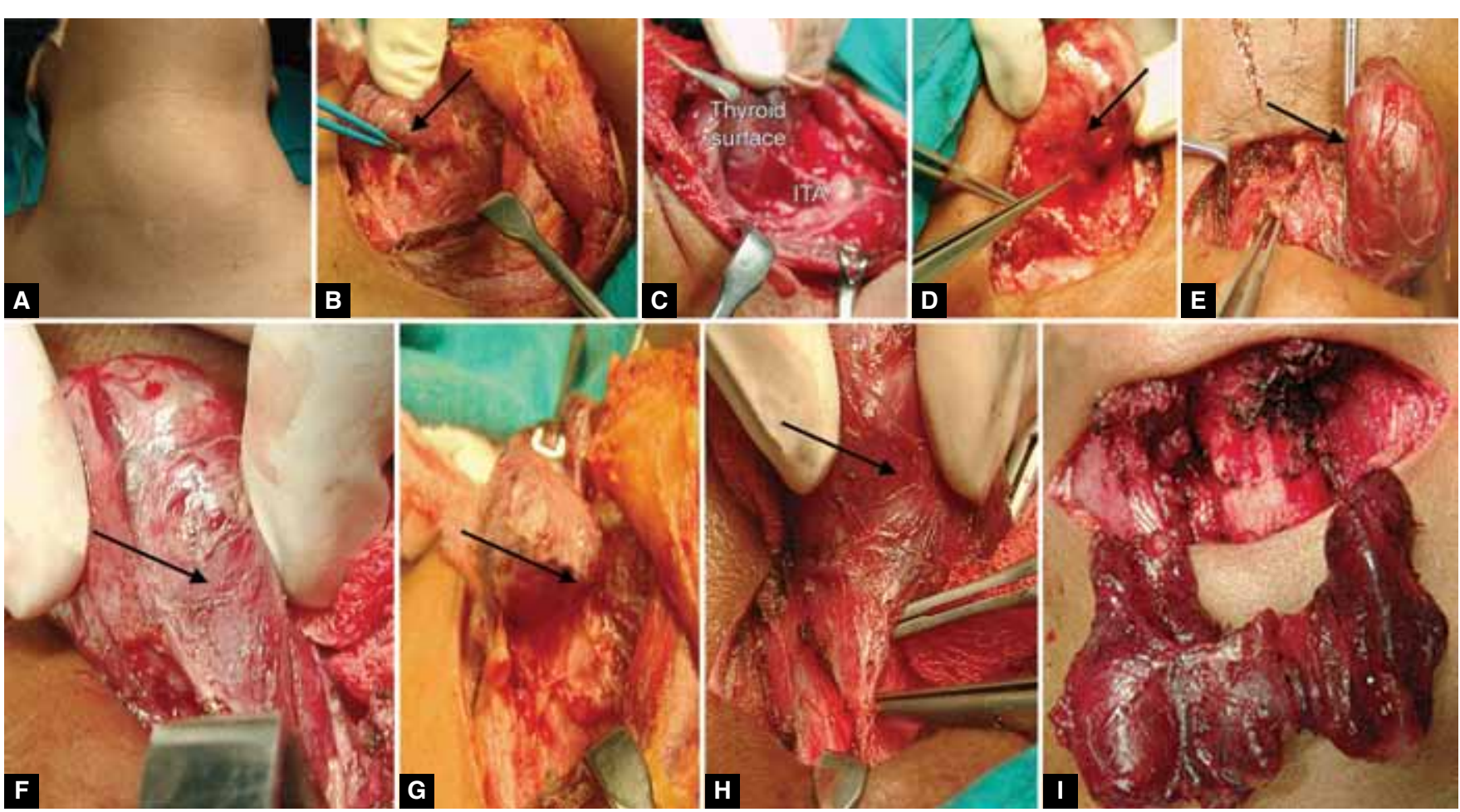

Figs 1A to I: Steps of PBC parathyroid-sparing thyroidectomy. Block arrows indicate plane of PCB dissection: (A) clinical photograph of goiter, (B) plane of dissection lower pole, (C) showing ITA and surface dissection is on surface of thyroid, (D) posteromedial dissection using pinch, burn and cut, $(E)$ showing parathyroid, $(F)$ one pole completely mobilized, $(G)$ recurrent laryngeal nerve, $(H)$ attachment at ligament of berry and (I) excised thyroid displaced

Recurrent laryngeal nerve was injured in 9 in group $\mathrm{A}$, 6 in group $C$ and none in group B.

A total of 34 out of 94 patients in group A, 1 out of 87 patients in group $B$ and 6 out of 11 patients in group $C$ had postoperative hypoparathyriodism.

And two patients in group A had secondary hemorrhage and one patient in group $C$ had secondary hemorrhage and no patient in group B had secondary hemorrhage.

Superior laryngeal nerve palsy was seen in 6 out of 94 patients in group A, 3 out of 94 patients in group C. Group B did not have any incidence of SLN palsy.

All patients are alive; one patient of group A required tracheostomy.

Most of the patients of groups A and C had calcium supplementations postoperatively.

Statistical analysis using tailed $\mathrm{t}$-test for all parameters showed $\mathrm{p} \leq 0.05$.

\section{DISCUSSION}

Thyroidectomy, total or subtotal, is the surgical treatment of choice for most of the goiter cases. Thyroidectomy was fraught with excessive bleeding and RLN palsy was common. ${ }^{1-3}$ Better understanding of thyroid surgery, improved surgical instrumentation, diathermy, enhanced surgical skills have reduced blood loss. ${ }^{4}$ Harmonic scalpel, LigaSure and minimal access thyroidectomy have all tried to reduce bleeding. In the present series, the authors have tried to compare conventional (pedicle thyroidectomy) with PBC parathyroid sparing surface thyroidectomy and harmonic scalpel. The blood loss was significantly more ( 100 to $500 \mathrm{ml}$ in group $A$ and 5 to $10 \mathrm{ml}$ in groups B and C).

Duration of surgery has not been discussed much in literature. Authors have tried to compare duration of surgery. All the three groups were nearly similar (120 minutes in group A, 90 minutes in group B, 100 minutes in group C). Intraoperative bleeding, postoperative bleeding, fear of surgical hematomas have been a concern. This has made the drain 'a must' in training and teaching of thyroidectomy. Ecker $\mathrm{T}$ et al, ${ }^{5}$ Soroush A et $\mathrm{al}^{6}{ }^{6}$ Yao HS et $\mathrm{al}^{7}$ showed use of harmonic scalpel reduced blood loss significantly. Authors in the index series showed blood loss was minimal with PBC parathyroid sparing surface thyroidectomy. LigaSure ${ }^{7}$ was quoted to be safe, effective and a quick alternative. ${ }^{7}$ LigaSure has not been used in present series. Surface thyroidectomy is of recent origin. ${ }^{8,9}$ Many techniques and anatomical details have been published to protect RLN injury. ${ }^{10,11}$ Pinch, burn, cut is the senior author's technique of surface thyroidectomy. Author's anatomical drawing clearly shows the plane of dissection in the surface thyroidectomy (Fig. 2). This plane is on the surface of thyroid just before the vessels enter the parenchyma of thyroid. At this level, the main vessels superior thyroid 


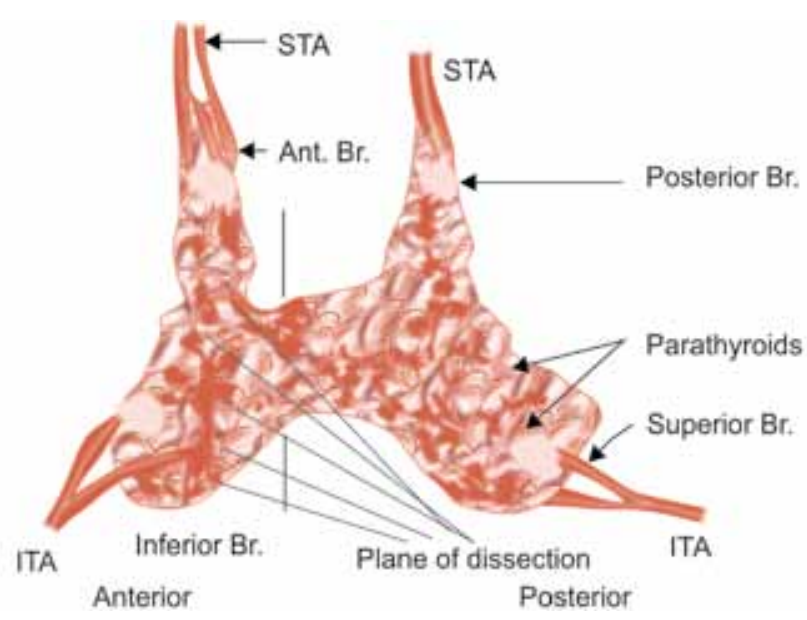

Fig. 2: Line diagram of surface dissection. The site of surface dissection shown by dark dots dissection is beyond main division of STA and ITA, thus keeps RLN and SLN from surgical injury dissection is distal to parathyroid gland, thus avoids ischemic injury to parathyroid

artery and inferior thyroid artery have already divided into two subdivisions. The vessels are very small and multiple as they enter parenchyma of thyroid gland. These small vessels are easy to PBC using? This makes every inch of dissection almost bloodless. This plane of dissection has been used by author in 87 thyroidectomies and has shown to be extremely effective in reducing blood loss, in making thyroidectomy dry and clean and in avoiding the routine drain.

Recurrent laryngeal nerve was and continues to be an Achilles heel in the surgery of thyroid. Pinch, burn, cut parathyroid-sparing surface thyroidectomy as described by the authors, both the nerves are at a safe distance. Use of low levels of current during PBC which also reduces lateral heat-related nerve injuries. In the present series, use of harmonic scalpel had one RLN palsy which might be due to transmitted heat from the tip of the instrument intraoperative nerve monitoring. ${ }^{11-14}$ Authors have not used intraoperative nerve stimulation due to lack of facility. But the plane of dissection as described by the authors is far away from the nerves. Additionally, conventional pedicle ligations, however, meticulously done cannot detect and avoid anomalous nerve vessel relation.

Postoperative hypoparathyroidism is yet another concern of conventional thyroidectomy. This has been mainly attributed to ischemia of parathyroid glands due to pedicle ligation. ${ }^{15,16}$ In the present index series using surface thyroidectomy, the hypoparathyroidism have been totally avoided while it was observed in 34 out of 94 patients in group A. Authors stressed the point that the surgical plane of dissections on the surface of thyroid between parathyroid and thyroid gland, thereby totally avoiding ischemia of parathyroid gland. Bleeding and secondary hemorrhage again was and is an issue in thyroidectomy. ${ }^{17}$ To avoid secondary hemorrhage, use of LigaSure and harmonic scalpel has not been known to reduce secondary bleeding significantly. This is simply due to large size of main arteries: superior thyroid artery and inferior thyroid artery. In the authors' technique of thyroidectomy, the vessels approached for PBC techniques are very small in size and help in avoiding secondary hemorrhage. Authors support PBC parathyroid-sparing surface thyroidectomy as a technique to reduce bleeding and secondary hemorrhage.

Redo surgeries pose a technical challenge to the surgeon, putting the RLN at risk and adhesions increasing the chance of bleeding. ${ }^{18}$ Surface thyroidectomy, on the other hand, approaches thyroid surface in a plane where the vessels are very small, thereby decrease per operative and postoperative bleeding.

\section{CONCLUSION}

Surface thyroidectomy is an effective, efficient, dissection technique based on anatomical distribution of blood supply. This plane of dissection is also the safest for RLN and SLN. Parathyroid glands are protected by default as the dissection is beyond the gland.

\section{REFERENCES}

1. Chen E, Cai Y, Li Q, Cheng P, Ni C, Jin L, Ji Q, Zhang X, Jin C. Risk factors target in patients with post-thyroidectomy bleeding. Int J Clin Exp Med 2014 Jul 15;7(7):1837-1844.

2. Osmólski A, Frenkiel Z, Osmólski R. Complications in surgical treatment of thyroid diseases. Otolaryngol Pol 2006;60(2): 165-170.

3. Calò PG, Pisano G, Piga G, Medas F, Tatti A, Donati M, Nicolosi A. Postoperative hematomas after thyroid surgery: incidence and risk factors in our experience. Ann Ital Chir 2010 Sep-Oct;81(5):343-347.

4. Molnar C, Voidazan S, Rad CC, Neagoe VI, Roşca C, Barna L, Copotoiu C. Total thyroidectomy with LigaSure small jaw versus conventional thyroidectomy-a clinical study. Chirurgia (Bucur) 2014 Sep-Oct;109(5):608-612.

5. Ecker T, Carvalho AL, Choe JH, Walosek G, Preuss KJ. Hemostasis in thyroid surgery: harmonic scalpel versus other techniques-a meta-analysis. Otolaryngol Head Neck Surg 2010 Jul;143(1):17-25.

6. Soroush A, Pourbakhtyaran E, Allame S, Zamani MM, Etemadi M, Nasiri S. Harmonic scalpel is more secure than conventional methods in total thyroidectomy: a randomized clinical trial. J Minim Invasive Surg Sci 2013;2(3):23-27.

7. Yao HS, Wang Q, Wang WJ, Ruan CP. Prospective clinical trials of thyroidectomy with LigaSure vs conventional vessel ligation: a systematic review and meta-analysis. Arch Surg 2009 Dec;144(12):1167-1174.

8. Lorente-Poch L, Sancho JJ, Ruiz S, Sitges-Serra A. Importance of in situ preservation of parathyroid glands during total thyroidectomy. Br J Surg 2015;102(4):359-367.

9. Delbridge L, Reeve TS, Khadra M, Poole AG. Total thyroidectomy: the technique of capsular dissection. Aust N ZJ Surg 1992 Feb;62(2):96-99. 
10. Aytac B, Karamercan A. Recurrent laryngeal nerve injury and preservation in thyroidectomy. Saudi Med J 2005 Nov;26(11): 1746-1749.

11. Varaldo E, Ansaldo GL, Mascherini M, Cafiero F, Minuto MN. Neurological complications in thyroid surgery: a surgical point of view on laryngeal nerves. Front Endocrinol (Lausanne) 2014;5:108.

12. Barczyński M, Konturek A, Pragacz K, Papier A, Stopa M, Nowak W. Intraoperatvie nerve monitoring can reduce prevalence of recurrent laryngeal nerve injury in thyroid reoperations: results of a retrospective cohort study. World J Surg 2014 Mar;38(3):599-606.

13. Hurtado-Lopez LM, Pacheco-Alvarez MI, Montes-Castillo Mde L, Zaldivar-Ramirez FR. Importance of the intraoperative identification of the external branch of the superior laryngeal nerve during thyroidectomy: electromyographic evaluation. Thyroid 2005 May;15(5):449-454.
14. Yagnik V, Mehta M. Incidence of recurrent laryngeal nerve palsy with and without nerve identification during thyroid surgery. Internet J Surg 2008;20(1):1-4.

15. ShiryazdiSM,KargarS, Afkhami-ArdekaniM,NeamatzadehH. Risk of postoperative hypocalcemia in patients underwent total thyroidectomy, subtotal thyroidectomy and lobectomy surgeries. Acta Medica Iranica 2014;52(3):206-209.

16. Huang C-F, Jeng $Y$, Chen K-D, Yu J-K, Shih C-M, Huang S-M, Lee C-H, Chou F-F, Shih M-L, Jeng K-C, Chang T-M. The preoperative evaluation prevent the postoperative complications of thyroidectomy. Ann Med Surg (Lond) 2015 Mar;4(1):5-10.

17. Siperstein AE, Berber E, Morkoyun E. The use of the harmonic scalpel vs conventional knot tying for vessel ligation in thyroid surgery. Arch Surg 2002 Feb;137(2):137-142.

18. Lefevre JH, Tresallet C, Leenhardt L, Jublanc C, Chigot JP, Menegaux F. Reoperative surgery for thyroid disease. Langenbecks Arch Surg 2007 Nov;392(6):685-691. 